\title{
Improved Corrosion Resisting Property of Magnetism Iron Fiber by $\mathrm{SiO}_{2}$ Coating
}

\author{
Dongying Niu, Jinku Yu*, Qi Qiao, Dongdong Wang, Runhai Liu \\ State Key Laboratory of Metastable Materials Science and Technology, Yanshan University, Qinhuangdao, China. \\ Email: "yujinku@ysu.edu.cn
}

Received February $22^{\text {nd }}, 2012$; revised March 25 ${ }^{\text {th }}, 2012$; accepted April $10^{\text {th }}, 2012$

\begin{abstract}
To improve the oxidation resistance property of iron fibers, a $\mathrm{SiO}_{2}$ coated iron fiber was prepared by sol-gel method, and its microstructure, element and phase composition, antioxidation property, and crystallization were characterized by scanning electron microscopy, thermal gravimetric analysis, $\mathrm{X}$-ray diffraction and $3 \% \mathrm{CuSO}_{4}$ solution dripping. It was found that the surface of the iron fiber can be fully covered with $\mathrm{SiO}_{2}$ by using sol-gel method. Our results also indicated that the time of iron begin to be corrupted in $3 \% \mathrm{CuSO}_{4}$ solution drip increased from $30 \mathrm{~s}$ to $240 \mathrm{~s}$, and the temperature increased from $200^{\circ} \mathrm{C}$ to $310^{\circ} \mathrm{C}$. In addition, the oxidation and antioxidation mechanisms of the $\mathrm{SiO}_{2}$ coated iron fiber have also been discussed in this work.
\end{abstract}

Keywords: Corrosion Resistance; Anti-Oxidation; Sol-Gel Method; $\mathrm{SiO}_{2}$

\section{Introduction}

Up to now, the most commonly used microwave absorbers are magnetic materials (such as ferrite particles) and dielectric materials (such as carbon black particles) [1-3]. However, the expansion of applications was limited due to their thickness and weight. Recently, some researchers has been devoted to the study of the electromagnetic properties of nonspherical magnetic materials [4-8], such as iron fibers (MIFs) etc. Owing to MIFs' unique properties, lower cost and important applications as functional microwave absorbing materials, the preparation and properties of MIFs have been investigated by many researchers $[9,10]$. To date, MIFs can be produced by bundle-drawing, melt-extraction, and chatter-machining [7, 11-16] methods. For example, MIFs with diameter less than $2 \mu \mathrm{m}$ have been prepared by using bundle-drawing method [7]. However, the MIFs easily oxidized in air, and this poor anti-corrosion ability prevents its wide applications. To overcome this disadvantage, many methods have been used to improve the anti-corrosion ability of the MIFs [17]. However, the anti-corrosion ability is not good enough. Therefore, a new technique is necessary to develop to improve the anti-corrosion ability of MIFs.

The sol-gel technique is a low-temperature route widely employed to prepare thin films for use in the different fields, because it can offer the homogeneous thin

"Corresponding author. films at molecular scale and control of chemical purity Recently, it has a rapid development in the field of machining electromagnetic materials and the interest to prepare the materials by sol-gel methods [18-19] has increased remarkably. Moreover, $\mathrm{SiO}_{2}$ has excellent insulation property and antioxidation property. To this end, a novel $\mathrm{SiO}_{2}$ coated MIFs has been developed by sol-gel technique in this paper. Our experimental results further demonstrated that the antioxidation property of the $\mathrm{SiO}_{2}$ coated MIFs has been improved evidently.

\section{Experimental Methods}

In this work, silicon dioxide sols were prepared by using tetraethoxysilane (TEOS) as precursor, ammonia water as activator and absolute alcohol as solvent. Firstly, 100 $\mathrm{ml}$ TEOS/alcohol solution was prepared by mixing TEOS with absolute ethanol at a molar ratio 3:10 of TEOS to $\mathrm{C}_{2} \mathrm{H}_{5} \mathrm{OH}$, and then $50 \mathrm{ml}$ ammonia water was added into the TEOS/alcohol solution smoothly under stirring simultaneously. After that, $10 \mathrm{~g}$ iron fibers were added into the above prepared solution, at the same time, the system was kept shaking and the temperature was kept at $25^{\circ} \mathrm{C}$ in water shaker for $30 \mathrm{~min}$. Finally, the iron

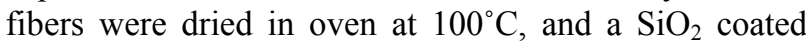
MIFs were obtained.

For passivation, a solution of chromiumtrioxide/ phosphoric acid/blackening agent/accelerant was prepared with molar ratio of $6: 3: 4: 15$ and the amount of the reagents in solution were varied in the range $20-35 \mathrm{~g}$. 
Then put the above treated MIFs into the passivation solution and passivating for 4 hours at $25^{\circ} \mathrm{C}$. After that, the final passivated MIFs were washed with distilled water and then dried in air at $60^{\circ} \mathrm{C}$.

To characterize the final obtained MIFs, scanning electron microscopy (SEM), thermal gravimetric analysis (TGA), X-ray diffraction (XRD) and $3 \% \mathrm{CuSO}_{4}$ solution dripping were used. In detail, SEM was used to observe the morphology of the films. Elements of the passivated films are conformed by using energy dispersive spectrum (EDS). Phase composition of the passivated films after heat treatment was identified by XRD. The thermal behavior of the samples was determined by TGA. 3\% $\mathrm{CuSO}_{4}$ solution drip was adopted to determine the anticorrosion property of the passivated films.

\section{Results and Discussion}

To study the morphology of MIFs before and after solgel processing, SEM is performed for the MIFs samples, and they are shown in Figure 1. The SEM images of the MIFs before and after treatment are shown in Figures 1(a) and (b), respectively. As can be seen from Figure 1, the surface of the MIFs without treatment was rough and full of drawing trace, which can improve the physics limitation and easily been corrupted. As shown in Figure 1(b), after sol-gel processing, the surface of the MIFs has been covered with $\mathrm{SiO}_{2}$ successfully.

In order to investigate the morphology of $\mathrm{SiO}_{2}$ coated MIFs after passivation, SEM is also perform for $\mathrm{SiO}_{2}$ coated MIFs after passivation, and shown in Figure 2. As can be seen from Figure 2, the surface of the MIFs has been covered with spherical $\mathrm{SiO}_{2}$ particles.

In this work, element distribution is also characterized by EDS for the $\mathrm{SiO}_{2}$ coated MIFs and the results are shown in Figure 3. It can be seen from Figure 3, besides of the peaks corresponding to $\mathrm{Ni}, \mathrm{C}, \mathrm{O}, \mathrm{Cu}$ elements, there are several characteristic peaks of $\mathrm{Fe}$ element, which attributed to the iron fibers. The $\mathrm{Si}, \mathrm{O}$ elements

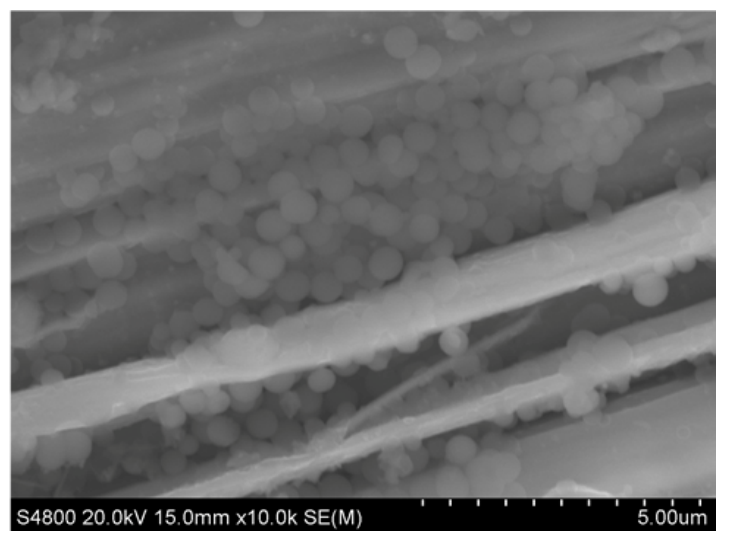

Figure 2. Surface appearance of the MIFs film after treatment under SEM. comes from the sol-gel method, and the Ni elements are obtained from the passivation. This result further indiated that the surface of the MIFs has been coated with $\mathrm{SiO}_{2}$ successfully, and this further confirms our previous SME results.

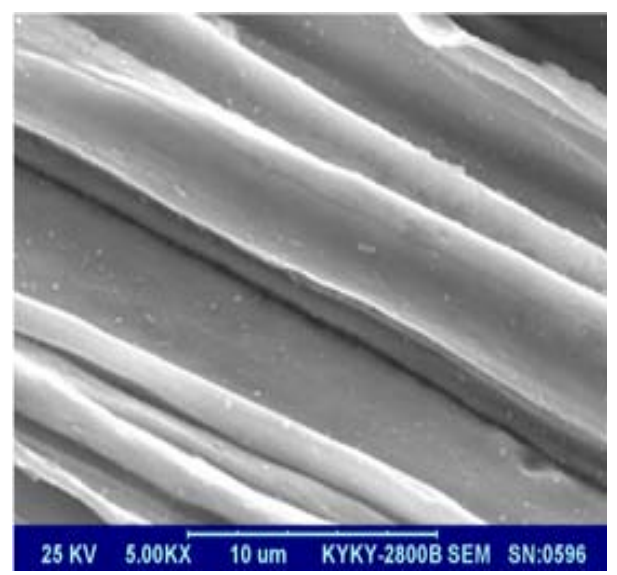

(a)

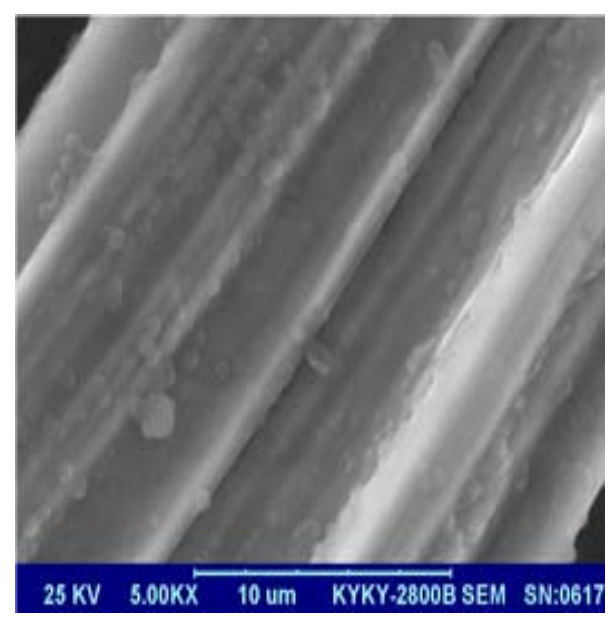

(b)

Figure 1. Surface appearance of the MIFs under SEM: (a) without treatment; (b) after treatment.

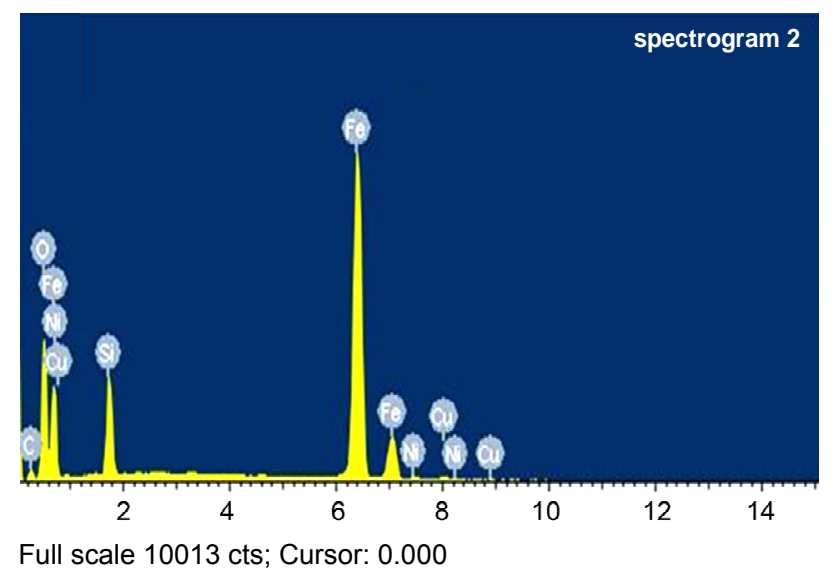

Figure 3. EDS analysis of the MIFs after treatment. 
In order to study the oxidation resistance property of MIFs after sol-gel processing and passivation, TGA experiments are performed for MIFs before and after solgel processing and passivation, and they are shown in Figure 4. It is found that the weight begin to increase at $200^{\circ} \mathrm{C}$ for MIFs without treatment, this means that the MIFs without treatment began to oxidize at this point. When the temperature reaches to $370^{\circ} \mathrm{C}$, the MIFs start to aggravate. Compared to the MIFs without treatment, the temperature for the treated MIFs begin to oxidize is $310^{\circ} \mathrm{C}$, and the aggravate temperature is $440^{\circ} \mathrm{C}$. Meanwhile, the increased weight of the treated MIFs is always less than the MIFs without treatment. These results indicate that the oxidation resistance of the MIFs is enhanced after sol-gel processing and passivation evidently.

To further study the oxidation resistance property and phase stability of MIFs after sol-gel processing and passivation, XRD experiments are performed for MIFs sample after heat treatment under $400^{\circ} \mathrm{C}$ for 3 hours, and they are shown in Figure 5. In this work, two kinds of MIFs samples were heat treated, one is the MIFs sample just after sol-gel processing, and the other one is the MIFs sample after both sol-gel processing and passivation treatment. It can be concluded from Figure 5, after heat treatment under $400^{\circ} \mathrm{C}$ for 3 hours, the XRD pattern of the MIFs sample just after sol-gel processing exists two main phases: pure iron and $\mathrm{Fe}_{3} \mathrm{O}_{4}$. But for the XRD pattern of the MIFs sample after both sol-gel processing and passivation treatment exist only one main phase: pure iron. These results imply that the oxidation resistance property of the sol-gel processing treated MIFs can be further improved by passivation processing. Our present results also consist with the previous TGA study, and further confirmed our previous experiments. The anticorrosion property of the MIFs was identified by 3\% $\mathrm{CuSO}_{4}$ solution drip and the result turns up to be: the anti-corrosion time of the MIFs after treatment increased from $65 \mathrm{~s}$ to $240 \mathrm{~s}$.

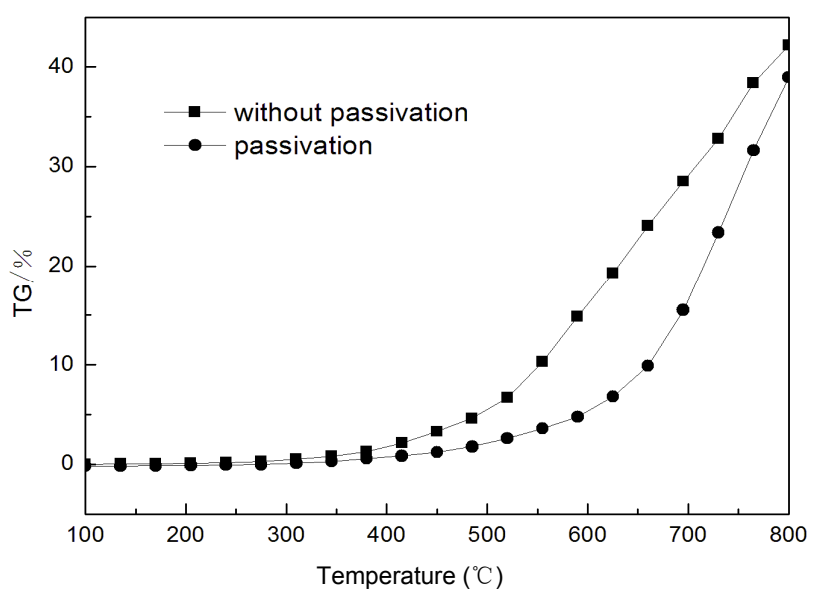

Figure 4. TG curve of the MIFs before and after treatment.

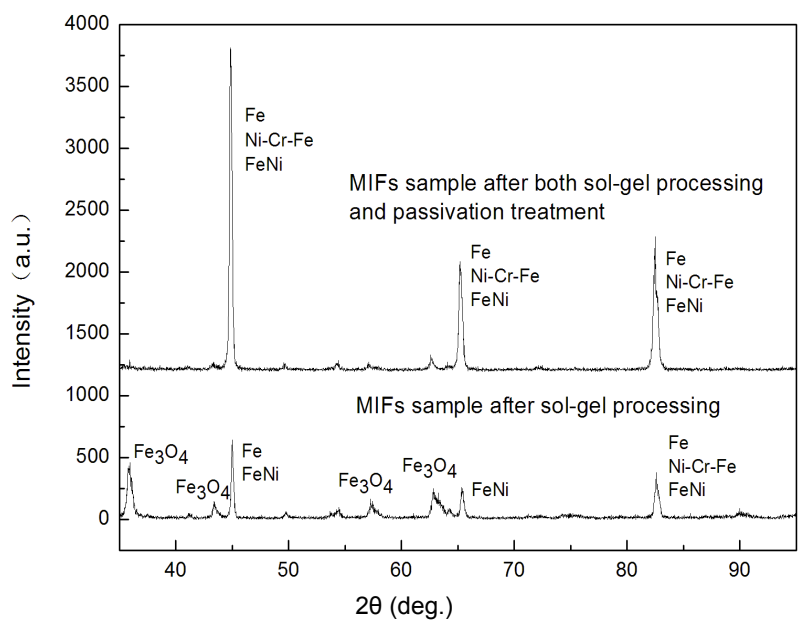

Figure 5. X-ray diffraction spectrum of the MIFs after heat treatment.

\section{Conclusion}

In order to improve the oxidation resistance property of MIFs, a novel $\mathrm{SiO}_{2}$ coated MIFs has been developed, and to further improve the oxidation resistance property of MIFs, a passivation processing was studied. The experimental results indicated that, the surface of the MIFs can be covered by $\mathrm{SiO}_{2}$ after sol-gel processing. The antioxidation property of $\mathrm{SiO}_{2}$ coated MIFs can be improved by further passivation treatment.

\section{Acknowledgements}

The authors gratefully acknowledge the support of the SIWEITE metal fibers company for providing the MIFs. Thanks are also made to Professor J. K. Yu and M. Z. Wang for help with experiments and valuable discussions.

\section{REFERENCES}

[1] X. D. Chen, G. Q. Wang, Y. P. Duan and S. H. Liu, "Microwave Absorption Properties of Barium Titanate/Epoxide Resin Composites," Journal of Physics D: Applied Physics, Vol. 40, No. 6, 2007, pp. 1827-1830. doi:10.1088/0022-3727/40/6/035

[2] M. A. Bhuiyan, S. M. Hoque and S. Choudhury, "Effects of Sintering Temperature on Microstructure and Magnetic Properties of $\mathrm{NiFe}_{2} \mathrm{O}_{4}$ Prepared from Nano Size Power of $\mathrm{NiO}$ and $\mathrm{Fe}_{2} \mathrm{O}_{3}$," Journal of Bangladesh Academy of Sciences, Vol. 34, No. 2, 2010, pp. 189-195.

[3] J. P. Zhao, Y. Li and P. L. Wu, "Recent Developments of Studies on New Electromagnetic Wave Absorbing Materials," Materials Science and Technology, Vol. 10, No. 2, 2002, pp. 219-224.

[4] Y. C. Qing, W. C. Zhou, F. Luo and D. M. Zhu, "Electromagnetic and Microwave Absorption Properties of Carbonyl Iron and Carbon Fiber Filled Epoxy/Silicone Resin Coatings," Applied Physics A, Vol. 321, No. 4, 2009, pp. 
$1177-1181$.

[5] L. C. Cheng, S. K. Pan, C. F. Lu and X. T. Luo, "Microwave Absorbing Property of Fe-Si-Cr Alloy Micropowders," Electronic Components and Materials, Vol. 30, No. 1, 2011, pp. 66-68.

[6] F. S. Wen, W. L. Zuo, H. B. Yi, N. Wang, L. Qiao and F. S. Li, "Microwave-Absorbing Properties of Shape-Optimized Carbonyl Iron Particles with Maximum Microwave Permeability," Physics B, Vol. 404, No. 20, 2009, pp. 3567-3570.

[7] H. F. Cheng, W. Xie, Z. Y. Chu, Y. J. Zhou, G. P. Tang and Z. H. Chen, "Effect of Grinding Techniques on Absorbing Characteristics of Short Iron Fibers," Journal of Wuhan University of Technology-Materials Science Edition, Vol. 22, No. 3, 2007, pp. 400-403.

[8] R. C. Pullar and A. K. Bhattacharya, "The Magnetic Properties of Aligned M Hexa-Ferrite Fibres," Journal of Magnetism and Magnetic Materials, Vol. 300, No. 2, 2006, pp. 490-499. doi:10.1016/i.jmmm.2005.06.001

[9] X. A. Fan, J. G. Guan, W. Wang, Y. L. Wang, G. X. Tong and F. Z. Mou, "Preparation, Microstructure Control and Magnetic Properties of 1D Ferromagnetic Metal Nanomaterials," Progress in Chemistry, Vol. 21, No. 1, 2009, pp. 143-151.

[10] A. Itou, O. Hashimoto, H. Yokokawa and K. Sumi, “A Fundamental Study of a Thin $\lambda / 4$ Wave Absorber Using FSS Technology," Electronics and Communications in Japan, Vol. 87, No. 11, 2004, pp. 77-86.

[11] M. Z. Wu, H. H. He, Z. S. Zhao and X. Yao, "Preparation of Magnetic Cobalt Fibres and Their Microwave Properties," Journal of Physics D: Applied Physics, Vol. 33, No. 22, 2000, pp. 2927-2930. doi:10.1088/0022-3727/33/22/309

[12] A. S. Antonov, N. A. Buznikov, A. B. Granovsky and N.
S. Perov, "Nonlinear Magnetoimpedance Effect in Soft Magnetic Amorphous Wires Extracted from Melt," Sensors and Actuators A, Vol. 106, No. 1-3, 2003, pp. 208211. doi:10.1016/S0924-4247(03)00168-7

[13] E. A. Aguilar and R. A. L. Drew, "Melt Extraction Processing of Structural $\mathrm{Y}_{2} \mathrm{O}_{3}-\mathrm{Al}_{2} \mathrm{O}_{3}$ Fibers," Journal of the European Ceramic Society, Vol. 20, No. 8, 2000, pp. 1091-1098. doi:10.1016/S0955-2219(99)00279-4

[14] X. Q. Shen, K. Cao, and J. X. Zhou, "Preparation of Ferromagnetic Binary Alloy Fine Fibers by Organic GelThermal Reduction Process," Transactions of Nonferrous Metals Society of China, Vol. 16, No. 5, 2006, pp. 10031008. doi:10.1016/S1003-6326(06)60368-3

[15] Y. J. Di, J. J. Jiang, D. U. Gang, B. Tian, S. W. Bie and H. H. He, "Magnetic and Microwave Properties of GlassCoated Amorphous Ferromagnetic Microwires," Transactions of Nonferrous Metals Society of China, Vol. 17, No. 6, 2007, pp. 1352-1357.

[16] X. L. Yu, X. C. Zhang and H. H. Li, "Simulation and Design for Stratified Iron Fiber Absorbing Materials," Materials \& Design, Vol. 23, No. 1, 2002, pp. 51-57. doi:10.1016/S0261-3069(01)00042-5

[17] Y. J. Zhou and H. F. Cheng, "Preparation of $\mathrm{SiO}_{2}$ Coating on the Surface of Microwave Absorbent by Sol-Gel Method," New Technology and New Process, No. 10, 2006, pp. 54-56.

[18] V. G. San and A. Morales, "Sol-Gel TiO Anti-Reflective Films for Textured Monocrystal-Line Silicon Solar Cells," Thin Solid Films, Vol. 403-404, 2002, pp. 335-338.

[19] M. M. Yusuf, H. Imai and H. Hirashima, "Preparation of Mesoporous $\mathrm{TiO}_{2}$ Thin Films by Surfactant Tinplating," Journal of Non-Crystalline Solids, Vol. 285, No. 1-3, 2001, pp. 90-95. doi:10.1016/S0022-3093(01)00437-9 